\title{
Commentary
}

\section{Ayushman Bharat: National Health Protection Mission}

\author{
Shubhangi Kalla ${ }^{1}$, Adrija Mehta ${ }^{2}$, Nayanika Sharma ${ }^{3}$, Anushka Sharma ${ }^{4}$ \\ ${ }^{1,2,3,4}$ MBBS Students, RUHS College of Medical Sciences and Hospital, Jaipur, Rajasthan, India
}

\section{INTRODUCTION}

Written in the history of Indian health care with red words, August 2017 was shadowed with grief and shame. In one of the most macabre and tragic incidents of recent times, more than 290 children died in BRD Medical College and Hospital in Gorakhpur in a span of three days as published in an Indian Express article on $30^{\text {th }}$ August 2017. The supplier allegedly cut supply of liquid oxygen after multiple unpaid bills. Blame is being ascribed to the government, hospital authorities, the supplier, and some are even saying this isn't about the oxygen shortage at all. Essentially, everyone involved has found someone to blame. The children, however, are dead. The families will have to live with this irreparable loss and immeasurable sorrow all their lives.

Even after 71 years of independence, the picture of Indian health care system is depressingly grey and grim. The high out-of-pocket expenditure and financial overburden that families continue to face in times of illness amongst both rural and urban population is alarming. The data is equally concerning as $62.58 \%$ of the total population pays their health and hospitalization expenses out of their own pocket and have no coverage or protection as such; which is by the way, the largest in the world.

The dearth of health care providers and adequate infrastructure is distressing especially in the rural areas, where 'catastrophic health expenses push populations the size of United Kingdom into poverty each year'. Adding to the numbers issued by Medical Council of India in 2017, there is one government allopathic doctor for every 10,189 people, one government hospital bed for every 2,046 people, and one state-run hospital for every 90,343 people. Hence, to say that our health care system is broken and needs revamping is an understatement.

\section{WHAT IS AYUSHMAN BHARAT ?}

The term 'Ayushman' means a long life. While this certainly isn't a reality for the moment, it was with this optimistic viewpoint that Hon'ble Prime Minister of India announced the launch of 'Ayushman Bharat-National Health Protection Mission' or the 'Pradhan Mantri Jan Arogya Yojana' on $15^{\text {th }}$ August, 2018. Through this scheme, the government plans to provide health insurance cover of up to Rs 5 lakhs per family per annum covering more than 10.74 crore poor and vulnerable families (approximately 50 crore beneficiaries) across the country. This ambitious scheme also aims to create around 1,50,000 Health and Wellness Centers which will bring health care closer to the homes of people. All pre-existing diseases from day one will be covered along with secondary and tertiary care hospitalization and the hospital can't charge any additional money from the beneficiaries of the treatment. What this scheme also aims to achieve is the strengthened public health care system, creation of health infrastructure, and increased health expenditure as percentage of GDP to help India achieve Universal Health Coverage and the Sustainable Development Goals.

Ambitious: most certainly. Feasible: maybe, maybe not!

\section{PROS AND CONS}

The Ayushman Bharat Yojana needs to be applauded on the grounds that it will attempt to lessen the sufferings of the poor and the deprived. Theoretically, Ayushman Bharat seems to be more promising than its predecessors like Rashtriya Swasthya Bima Yojana (RSBY) which had guaranteed to provide enrolment for health coverage, but the beneficiaries remain unidentified. As per the latest Socio-economic Caste Census (SECC) data covering both rural and urban areas, Ayushman Bharat claims to provide to 10.74 crore families annually, a sum of 5 lakhs compared to Rs 30,000 under RSBY. The scheme is designed to be dynamic and aspirational and it would take into account any future changes in the exclusion/ inclusion/ deprivation/ occupational criteria in the SECC 
data. RSBY had offered 70 packages while this scheme offers a hundred and thirty five and has also fixed the prices 15-20 percent less than the CGHS.

This scheme not only promises to cater to a large segment of the underprivileged population of our country, but it will also release the undue pressure that has been created over the government hospitals. Now that the private hospitals have been roped in this scheme, there will be a spirit of healthy competition prevailing. The government hospitals too, left with no alternative will have to better themselves since now they will have to compete against the high standards set by the private set up.

'I can do it all, I will do it all' said no wise leader ever. Strong leadership revolves around adequate distribution of responsibilities and accepting one's own limitation. While the government healthcare institutions have been disappointing in the very least, they have still maintained fairly decent financial institutions, LIC for instance is one of the country's most successful insurers. Therefore, it seems fair and wise for the government to be more involved in doing what it does best, providing monetary support.

Narayan Murthy has wisely stated, "Health is a major speed breaker towards the economic growth of our country". Ayushman Bharat thus comes as an acceptable alternative seamlessly for the economy and health care. Billed as the 'world's biggest public health care program' and a 'reform that will be visible from space' no doubt that this 'too good to be true' almost magical scheme looks alluring on paper. It doesn't come without certain concrete loopholes which might need to be tackled wisely. The devil here, lies in the details.

The budgetary allocations granted a sum of Rs 2,000 crore for this titanic scheme, which according to various sources will be grossly inadequate. Crude infrastructure facilities especially in rural areas and lack of workforce are issues that still need to be outlined in detail. While the government intentions are surely great, the implementation still remains cloudy. Moreover, the government has routed the payments via the private insurance companies to the hospitals, making them the biggest profit gainers of about $30 \%$. The extremely low package rates issued under Ayushman Bharat have made it impossible for many hospitals to thrive, while maintaining their standards. Private hospitals are ergo, unwilling to be a part of it.

\section{CONCLUSION}

India's billion beats will need more than an Ayushman Bharat, but for now it appears to be the policy decision in the correct direction. Looking beyond the issues and concerns, in a country like India where millions fall below poverty line, this scheme shall become a miracle, if it manages to reach the right places and be tabled with sincerity. Poverty due to health care is the Achilles tendon in India's health system and in trying to tackle this, the most deprived portion of India's population has obtained crucial support. Ayushman Bharat is an ambitious scheme, and something so humongous in size will have to go through painful transitions before it reaches its desired goals. With the potential of being a game changer, implementation of this scheme is what is most crucial, which will decide how the picture of the health sector looks like a few years down the line; whether quality, treatment, prevention and rehabilitation reaches everyone especially the most vulnerable, marginalized or not.

The government will have to be cognizant of the ground realities and develop a mechanism to monitor the health quality to yield maximum output. It will definitely be a learning curve for all stakeholders of society, public or private together working towards a common goal i.e. HEALTH FOR ALL. The elephant of health care might be diseased and weak for now but it sure has taken the first step towards being stronger and resilient.

\section{Footnote}

This is a summary of a debate at RUHS College of Medical Sciences, Jaipur.

\section{Corresponding Author}

Adrija Mehta, B-203, Pearl Green Acres, Shri Gopal Nagar, Gopalpura bypass, Jaipur, Rajasthan, India. PIN302019.

email: adrijamehta9931@gmail.com 